\title{
A escrita digital em scraps e a escrita de bilhetes em sala de aula: um estudo sobre transmutação de gênero textual
}

Verena Santos Abreu*

Resumo: Com base na Linguística Textual e na concepção de gêneros discursivos de Bakhtin ([1979] 2003), bem como nos estudos sobre Hipertexto e gêneros digitais, neste trabalho aparece como tema a escrita digital e sua influência na grafia de jovens em ambiente escolar, sobretudo na produção de bilhetes, fora do ciberespaço. Os corpora investigados são scraps extraídos do Orkut e bilhetes produzidos durante a aula de Língua Portuguesa/Redação, por estudantes do Ensino Fundamental II. O objetivo principal é analisar a recorrência de realizações de escrita que sugerem uma proximidade à linguagem digital, e a migração da escrita digital para um suporte diferente da tela do computador. Os resultados apontam para a possível transmutação da transmutação, uma vez que a escrita de um gênero transmutado (scraps) parece migrar para o gênero anterior (bilhetes), com vários registros similares à escrita digital.

Palavras-chave: Gêneros; Transmutação; Orkut; Scraps; Bilhetes

Abstract: Reasoned on the theoretical perspective of Textual Linguistics and based in the concept of genres of Bakhtin ([1979] 2003), as well as in studies on Hypertext and digital genres, digital writing and its influence in the writing of young people in school, mostly in communicative situations of production notes

Professora assistente, em regime temporário, da Universidade Federal do Recôncavo da Bahia (UFRB) - Centro de Ciências da Saúde. Mestre em Estudo de Linguagens pela Universidade do Estado da Bahia (UNEB). E-mail: veuabreu@hotmail.com 
and memos outside cyberspace, appears as theme in this present study. Scraps taken from Orkut social network and memos produced during Portuguese classes are the corpora investigated in this study. Therefore, one goal of research is to analyze the recurrence of realizations of writing that suggests closeness to the digital language, in order to investigate its influence on the spelling of young Internet users, and the transfer of the digital writing to another support that is not the computer's screen. The results show the possible transmutation of transmutation, furthermore when it was suggested to students writing notes and messages, although they use the paper as support, it was observed that many of them use words that have similar spelling to digital.

Keywords: Genres; Transmutation; Orkut; Scraps; Notes; Digital writing.

\section{Introdução}

Com o propósito de ampliar o debate em torno dos estudos sobre a escrita digital e a transmutação dos gêneros, no presente artigo, aparece como tema a escrita digital e sua influência na grafia de jovens em ambiente escolar, sobretudo em momentos comunicativos mais informais, com a produção de bilhetes, fora do ciberespaço. Destarte, o trabalho tem como alicerces teórico-metodológicos a Linguística Textual, bem como a noção multidisciplinar desta e de texto enquanto um evento linguístico social e cognitivo, de natureza comunicativa, conforme define Marcuschi (2003). Também endossam o presente trabalho as noçôes de gêneros textuais, sobretudo os estudos de Bakhtin ([1979] 2003), em especial os que abordam a transmutação dos gêneros. Junto com tais estudos aparecem as discussões acerca dos gêneros emergentes, os quais, segundo Marcuschi e Xavier (2004), se poderia chamar de gêneros digitais. Dentre esses, muitos apresentam uma escrita característica: a linguagem da Internet, também chamada de linguagem digital ou internetês. 
Baseando-se na fundamentação teórica adotada e a partir dos corpora extraídos de atividades de Português/Redação realizadas em âmbito escolar e scraps produzidos/lidos por usuários do Orkut, também em idade escolar, faz-se uma correlação entre o estudo de transmutação dos gêneros discursivos em Bakhtin ([1979] 2003) e a escrita digital presente em scraps no site de relacionamentos em questão.

Assim sendo, a metodologia mais aplicada aos propósitos deste artigo é a pesquisa de campo. Os corpora são atividades escolares (redações) de Língua Portuguesa/Redação, de alunos de uma escola particular, localizada em Santo Antonio de Jesus (BA), e scraps disponíveis no site de relacionamentos Orkut, escritos por jovens (integrantes de comunidades virtuais, nas quais se declaram pertencentes ao Ensino Fundamental II), para caracterizar a notação escrita digital e ilustrar inúmeras de suas realizaçôes no hipertexto. Assim, a seleção do corpus referente às atividades escolares foi realizada com 96 estudantes do sexto ao nono ano do Ensino Fundamental II, sendo os textos coletados durante um mês.

\section{Considerações sobre gêneros discursivos e transmutação}

$\mathrm{Na}$ concepção de Bakhtin ([1979] 2003), o uso da língua exige do falante, dentre outras coisas, a escolha do gênero discursivo mais adequado. Os gêneros, na perspectiva bakhtiniana, são tipos de enunciados relativamente estáveis, caracterizados por um conteúdo temático, com uma construção composicional e um estilo.

Há um conjunto de gêneros textuais emergindo com a Internet, mesmo a maioria deles tendo outros similares em outros ambientes comunicativos, tanto orais como escritos. Nesse sentido, pode-se concordar com Marcuschi (2002, p. 13) quando nos diz que "[...] os ambientes virtuais são extremamente versáteis e 
hoje competem, em importância, entre as atividades comunicativas ao lado do papel e do som [...] a Internet é uma espécie de protótipo de novas formas de comportamento comunicativo".

Bakhtin ([1979] 2003) exemplifica o caso da transmutação do diálogo cotidiano para a esfera literária, no qual aquele é absorvido e reinterpretado para o romance, passando a uma esfera mais complexa. Considerando a transmutação dos gêneros aliada ao avanço tecnológico, especialmente da Internet, Araújo (2003) defende a ideia de que o chat é oriundo do que Bakhtin chama de diálogo cotidiano, pois marcas do diálogo face a face permanecem no chat, mesmo em condições de produção e suportes físicos distintos, tornado-o um gênero emergente. Nessa vertente, considera-se o scrap do Orkut a transmutação do bilhete.

Para ilustrar a escrita em situaçốes reais de interação no Orkut, considerando a Linguística Textual e sua concepção da linguagem como atuação sócio-comunicativa inserida numa situação específica, foram selecionados scraps. Assim, abreviações, outra maneira de marcar acentuação, uma escrita semelhante à fala, utilização de símbolos matemáticos e a repetição de vogais ou consoantes para expressar uma ideia podem ser acompanhados nos exemplos a seguir, excertos de comunicação do Orkut.

Figura 01: linguagem digital em scrap
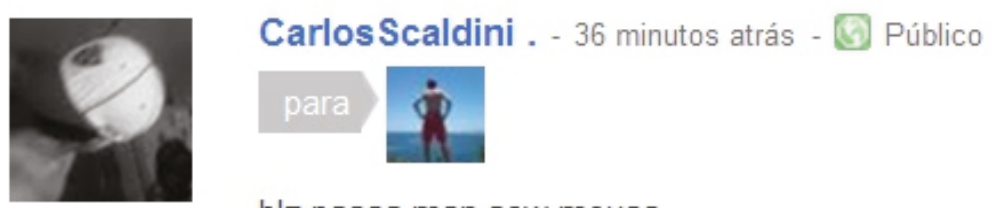

blz passa msn aew mouss

Figura 02: linguagem digital em scrap 


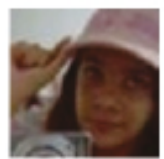

- 'Jeeeeh' "Oliveir@@@@" - 11/24/2008 - B Püblico
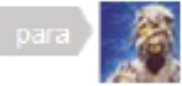

Pquc naum vai lá em casa???

Figura 03: linguagem digital em scrap

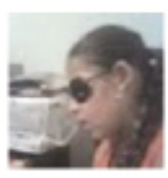

Bruna Vireque - 6 fev - (2) Püblico
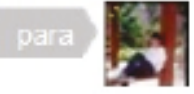

ooooiiiiii iiiii rodrigo tudo bem com ve $\eta 7$ estou com xaudades o meu msn è maezinha fị̆hotmail com

bjs ti doluu !!!!!!!!!!! FUI FUI FUI

Figura 04: linguagem digital em scrap

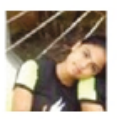

- Livia Cardoso '-' - 4 dez - B Público

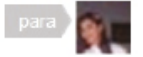

tambem naun amor.....

e muito obg... vc tambern e 1 otima pessoa.... e claro ke sim seremos otimas AMIGAS... BEIJÄO .... Fikj comDEUS pois ele ty ama.... ah e naum desista naum.....somos navas ainda tem tempo..

Figura 05: linguagem digital em scrap

Figura 06: linguagem digital em scrap

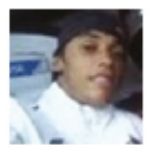

${ }^{* * B i N h o .0 * *}$ C.F -22 nov - (b) Público

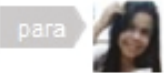

-Oii meu anjo tudo bem ???

To passando pra te deixar um enorme Bjo

e agradecer o seu recadinhoo.

Ah vc estah vacillando comigo hein.. nem tah falando comigo no msn neh 

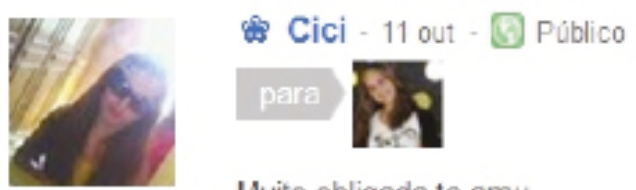

Muito obligada, te amu

bjokas

Figura 07: linguagem digital em scrap
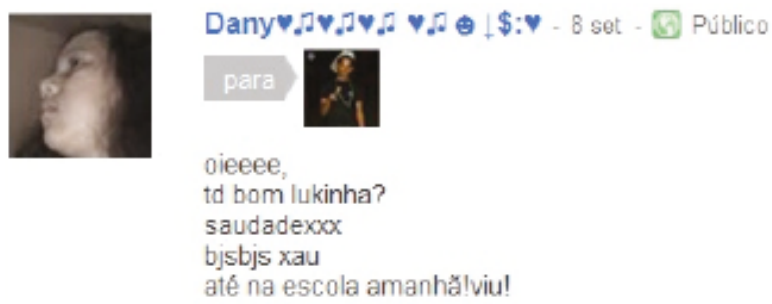

oieeee,

td bom lukinha?

saudadexxx

bjsbjs xau

até na escola amanhằ viu!

Figura 08: linguagem digital em scrap

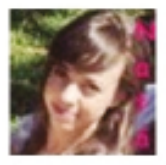

NataaLýa Saantoos. ' - 15 set - D Público
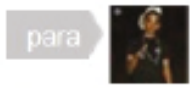

tbmm Teamo

vs mora aq. $\mathrm{OO} \rightarrow \longrightarrow<$

BeijOoo.... ${ }^{x}{ }^{x}$

Figura 09: linguagem digital em scrap 

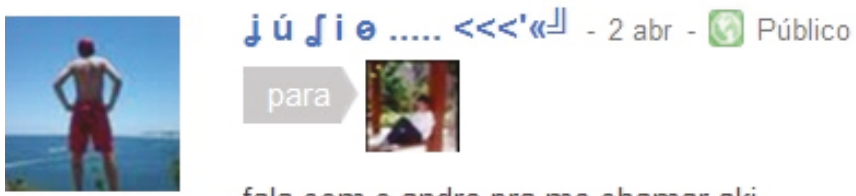

fala com o andre pra me chamar aki

Figura 10: linguagem digital em scrap
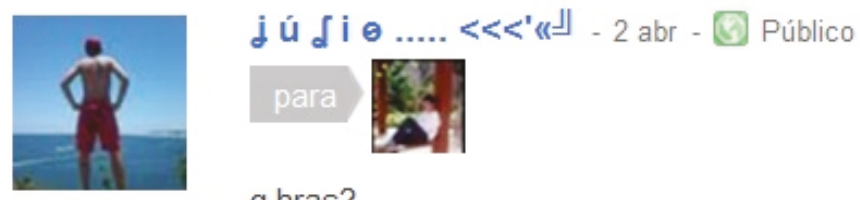

q hras?

Figura 11: linguagem digital em scrap

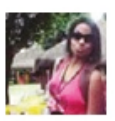

@IngridDJ $\rightarrow$ Equipe New Age Sound - 1 jul - B. Público

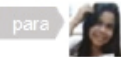

Aiiii iiiiiiiin to morrendo de saudades de tu $\nearrow^{\prime}$

Teeeeeeeeeee

amo0000000000000000000000000000000000000000000000000000000000000000000000000000000000 mto s2 1

Figura 12: linguagem digital em scrap

Figura 13: linguagem digital em scrap

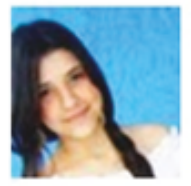

Leтícıа Sтнеffanє - 18 set - (4) Público

para

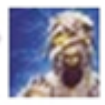

Queem eh??? 


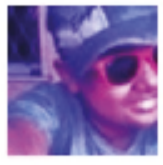

Renn@n@@idrade (NtX...) $\oplus-25$ mai - D Público

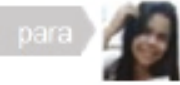

ESTOU COM MT SAUDADES D VC BJS

Figura 14: linguagem digital em scrap
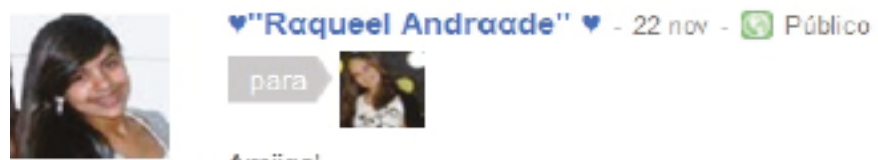

Amiiga'

Saudades dee vooc'

taa booa?

akii vaai viir aki no cultoo sabado?

se foor me respoondee

que ail eu encontroo coom vooc ee te liigoo

beeijaooo

Figura 15: linguagem digital em scrap

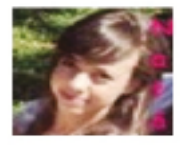

Nataalýa Saantoos. ' - 14 dez - @ Público para

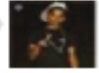

Taambééim tee amoo Amiigoo'h ..s2'

Figura 16: linguagem digital em scrap

Figura 17: linguagem digital em scrap

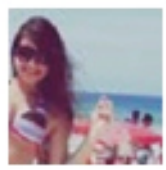

rafa almeida . - 10 out - (6) Público
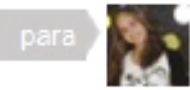

mtt obgd amr:)

tudo em dobrol te amo mttt \$2 
INGRID MARTINS - 23 nov - pelo orkut para celular - S) Público

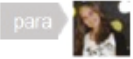

oi amor da tia gui,ta td bem, aqui ñ foi nd, só uma lembr. Eu adorei a festa, tava td lindo, e sobre a sua tia ñ tenho $\mathrm{cm}$ ligar p ela!? vou dar um jeito d ir lá.obrgd. pelo recds.billuss5.

Figura 18: linguagem digital em scrap
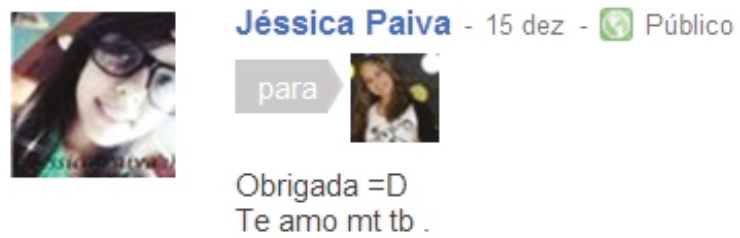

Figura 19: linguagem digital em scrap
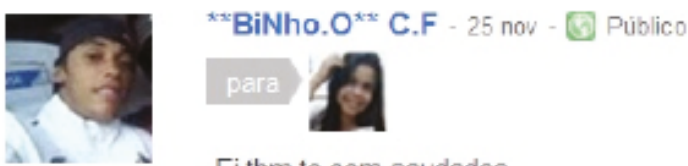

-Ei tbm to com saudades um bja0o pra vc tbm c cuidaa hein $=\mathrm{DDD}$

Figura 20: linguagem digital em scrap

Figura 21: linguagem digital em scrap

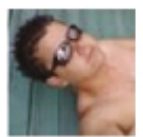

GoOrdinho Na Paz - 15 jul - D Público

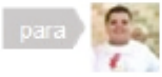

iai m/q . nem deus pra joga na conta ainda. se pà logo mais eu jogo.

falow.. 

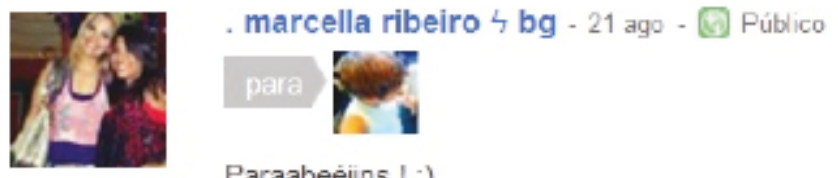

Paraabeeiins ! :)

Figura 22: linguagem digital em scrap
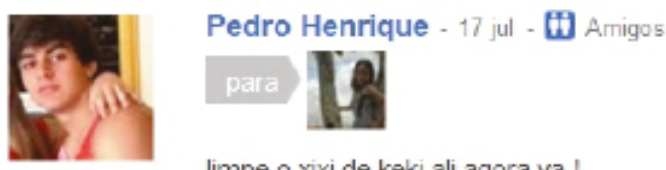

limpe o xixi de keki ali agora va ! kkkk

Figura 23: linguagem digital em scrap
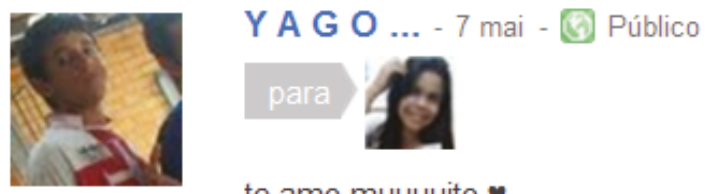

te amo muuuuito $\mathbf{v}$

Figura 24: linguagem digital em scrap

Figura 25: linguagem digital em scrap

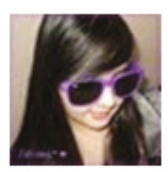

Júllia Almeiida ; ${ }^{*}$ - 10 dez - (4) Público
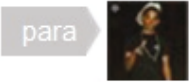

vlw Lukiinha bjs!! 


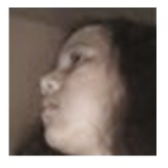

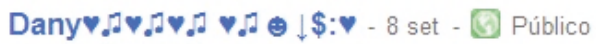
para

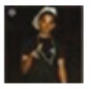

brigaduuuuu

pow valew

Figura 26: linguagem digital em scrap

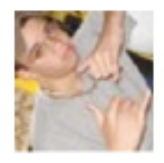

$\gg P € \boxminus \circledast \emptyset \mathrm{TM}<$ Š
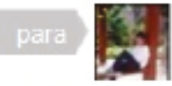

parabèns aew vey

Figura 27: linguagem digital em scrap
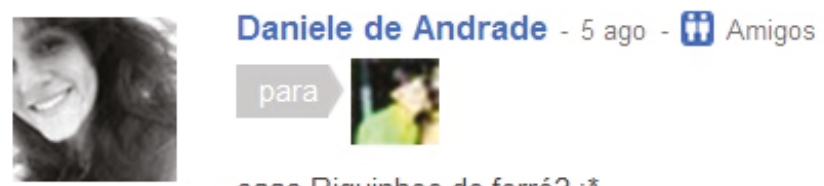

eaae Riquinhoo do forró? :*

Fig. 28: linguagem digital em scrap

Figura 29: linguagem digital em scrap

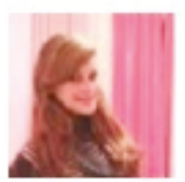

*** LanaH Ferreira** -16 set - [2] Publico
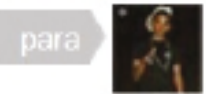

tbm meu anju mora akee

s2

lanah akiii" 


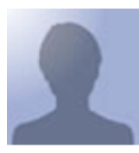

DSTV .Isabella Vieira *** - 08/05/2010 - (4) Público
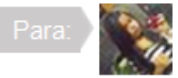

amg eu te amo mt

com voce eu aprendi mt, até andar de bike nunca nunca vou esquecer voces

voce e seu irmao sao as melhores coisas que apareceram na minha vida Suzana e Kevin S2 ETERNAMENTE

EU AMO VOCES

ESPERO QUE VENHA NOS VIZITAR.

BEIJOS

DANÇA BASTANTE A DANÇINHA DO CÚDURO.

$(\mathrm{L})(\mathrm{L})(\mathrm{L})(\mathrm{L})$

Figura 30: linguagem digital em scrap
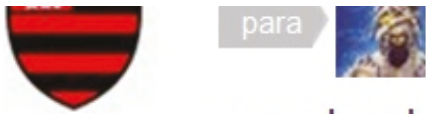

aeee.. descobri uma coisiiinha $=\mathrm{P}$

Aqora eu sei como deixar o orkut color do *-......*

Figura 31: linguagem digital em scrap

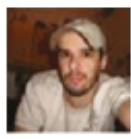

เēøn்ąrđø đẽ Erêîtą\$ - 27 nov - (5) Püblico

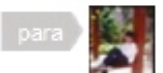

tricolor faz isso ai oh

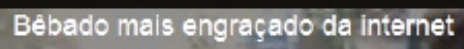

Figura 32: linguagem digital em scrap 


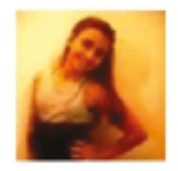

\section{Geovana Nogueira - 05/04/200B - (3) Público}

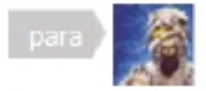

hauhauahuh

lindo

bjj

\section{Análise da escrita em bilhetes produzidos em sala de aula: semelhanças com a escrita dos scraps?}

Ao longo desta seção, foram transcritos bilhetes produzidos por 56 dos 96 alunos envolvidos na pesquisa. Esses 56 discentes escreveram, em seus textos, palavras que apresentam uma grafia semelhante às do corpus extraído do Orkut. Tais palavras foram destacadas, em negrito, pela autora e subdivididos por ano escolar dos discentes.

Inicialmente, dispõe-se o corpus recolhido no $6^{\circ}$ ano do Ensino Fundamental, que totaliza 25 bilhetes, sendo que 10 desses não apresentaram nenhum traço de escrita digital. Já os outros 15 bilhetes foram transcritos e analisados a seguir.

Quadro 1:

E aí miga tudo blz estou com saudades nunca + eu te vir faz um tempão que agente não conversa.

Pq vc não entra + no MSN e no Orkut, todos os dias eu entro no msn para tentar conversar com vc + não consigo.

T+miga $\quad$ Beijos... Te Dollo 
Oi amigha vc sabi que eu gosto muito de vc; vc moxinha é muito importante para minha vidinha, apesar de vc ser minha prima do coração Te amo d+

Quadro 3:

Faz um bom tempo ke a gente num se vê por aí neh?

E as 9vidades como vão em? a família, como ke tá hem?

Bjoka

TE DOLLO

Quadro 4:

Oi meu amor!

É que estou morrendo de saudades, e queria dizer que cada dia que passa eu gosto mais de você. Beijos Xau!!!

Quadro 5:

olá riqueza, td bem? Estou com saldades! Vc sumiu, eu mandei várias mensagens no MSN, Orkut e vc nunca respondia.

Te dollo miga! Xau!!!

Quadro 6:

ola!

Querido amigo, você não sabe como meu final de semana foi otimo, teve um anivesario na casa do vizinho. XAU, XAU Bjssssss

Quadro 7:

Amiga

Olá amiga a sua amizade pra mi é de extrema importância pois vc me fez uma pessoa que todos querem hoje.

\section{Quadro 8:}




"Para minha"
Querida amiga"
Estou lhe escrevendo para dizer a vc que lhe amo muito no fundo
do meu coração..
Não sei se vc gosta de mim como eu gosto de vc. Pois fique
sabendo que por mim nossa amizade nunca acabara.
Vc não é só uma amiga para mim vc e como una irma. pois todas
as vezes que preciso de um ombro amigo vc esta ao meu lado

Quadro 9:

AMIGA VOCÊ TEM TUDO PARA SER FELIZ:

PAZ AMOR CARINHOSA CARISMATICA PACIENTE Bjss! Sucesso!

\section{Quadro 10:}

\section{E aí miga td blz?}

Estou com saudades, já faz um tempão q ñ nos falamos.

Pq vc ñ acessa o Orkut, quero saber das 9vidades,

Quem sabe eu não vá Ihe vizitar. Xau

\section{Quadro 11:}

Querida Amiga do SZ

Eu Amu a sua Amizade

AMIZADE mas que Eterna Amuuu Tú 
Quadro 12:

Querida amiga

Com esse seu jeito meigo, especial e carinhoso de ser você alegra todos ao seu redor e torna todo instante em um momento único e especial!

Você mora aki oh $\gg \gg \gg>>\quad \quad<<<<<<$

Sua simples existência me faz feliz!

TE ADOOORO DE MONTÃO!

Quadro 13:

Alô, miguxa

Tu sabe que eu te dollo, né?

quando eu te vejo fico assim =D

Ps: Quer dizer eu fico sempre assim né

Más tu mora aki oh $\gg \gg>\quad$ > >

Tu é para mim a melhor miguxa

espero q eu seja pra vc tb. Bjaao!

Quadro 14:

Neneim vc sabe $\mathbf{q}$ eu te considero mto e q na minha vidaã vc eh essenciaal u.u

Ps.. Neem eh noovidaade u.u

Tee deseiijo tuudo de boom amr pq eu tee amo mt. A nossa amzd vaai durando assiim, agnt briiga, agnt chora (sôo eu U.U) mais agente se ama.

Bzu

Da sua dona HAHAHA 
Quadro 15:

Boa tarde amiga

Me ligue!

te adollo

No recado exposto no quadro 1 destaca-se a escrita "blz". Tal realização representa a redução da palavra "beleza”, destarte, observa-se a sequência de consoantes representando palavras, sem uso de vogais. Um exemplo excerto do Orkut, comprova a realização dessa grafia em scraps de adolescentes, como ilustra a figura 01. Essa abreviatura da escrita também aparece no bilhete exposto no quadro 10 e apresenta a mesma carga semântica.

Outra grafia que merece destaque no bilhete transcrito no quadro 1 também sugere redução de palavra, apenas pelo uso de consoantes: "pq" e "vc", indicando, respectivamente, "por que" e "você", na escrita convencional. A mesma grafia para a expressão "Por que você" ("pq vc") foi encontrada no scrap evidenciado pela figura 02 e trata-se de uma realização bastante comum nas páginas do Orkut. Corrobora-se Bisognin (2010, p. 85), quando este pondera sobre o não prejuízo dessa escrita na compreensão por parte dos usuários da Internet:

Normalmente lemos uma abreviatura como uma palavra inteira, a forma resumida é apenas um substituto da palavra. Quando, no "internetês", aparecem "tb" ou "vc" ninguém que domina esse código vai ler "tebê" ou "vecê", mas lerá "também" e "você".

Ainda na análise do primeiro bilhete, a estudante utiliza o termo matemático "+".

Algumas palavras da escrita tradicional são transformadas em símbolos ou desenhos, como acontece com o sinal "+" para indicar "mais" ou, mais raramente, para indicar a conjunção "mas", a forma gráfica “_” para "menos", e o "T+" para até mais. (BISOGNIN, 2010, p. 85)

Dessa forma, as três possibilidades de significação para o ícone "+" aparecem no bilhete: "Pq vc não entra + no MSN e no Orkut...", onde "+" indica "mais"; " ...todos os dias eu entro no 
msn para tentar conversar com vc + não consigo", substituindo "mas" ; e também aparece junto a uma letra: "T+", simplificando a frase "até mais".

Para finalizar a análise do primeiro bilhete, destaca-se a expressão "Te Dollo", que aparece também no quadro 3, cuja forma de escrita varia um pouco dentro do próprio Orkut, como na realização de "ti doluu", presente na figura 03, que, apesar de diferente grafia, apresenta o mesmo som e significação. “ [...] chama a atenção a expressão 'te dollo', registro também comum em scraps do Orkut, que indicam afetividade, uma possível imitação da fala infantil, e representam semanticamente 'te adoro' " (ABREU, 2010, p. 201).

Prosseguindo análise, no segundo bilhete de uma aluna do $6^{\circ}$ ano, aparecem, além da grafia "vc", já analisada, as realizações "amigha", "moxinha" e "d+". Na Internet, especialmente no MSN e no Orkut é comum a existência de várias formas para um mesmo vocábulo, assim, nesse sentido, a palavra "amiga" encontra uma série de grafias para representá-la, denotando certa intimidade, como no caso de "amigha" (quadro 1), "miga" (quadros 1 e 5) e "miguxa" (quadro 15). Além disso, o uso do " $h$ " muitas vezes na linguagem digital se dá para sugerir, na escrita, alguma ênfase possível apenas na fala, como a realização de "Amiigoo'h", indicado pelo scrap da figura 15.

Já a utilização do " $x$ " na escrita de "moxinha", em vez de "mocinha", indica uso do "miguxês", assim como o vocábulo "miguxa", presente no bilhete exposto no quadro 15. Como já foi mencionado no capítulo anterior, o uso exagerando do " $\mathrm{x}$ ", marcando hábitos gráficos, caracteriza o "miguxês", que apresenta vários adeptos no Orkut. A figura 03, com a grafia "xaudades", ajuda a ilustrar tal "idioleto", conforme a concepção de Bisognin (2009).

Mais uma vez, o símbolo "+” aparece e, assim como em "T+", associado a uma letra. Na expressão "Te amo d+", o último termo representa "demais". Abreu (2010, p. 201) destaca dentre os bilhetes analisados 'a construção 'di+', tornando-se 
interessante ressaltar o uso do símbolo matemático (ícone) 't' para emitir as mensagens e representar a palavra 'mais"'.

Ao enfocar o bilhete transcrito no quadro 3, destaca-se mais uma realização da escrita digital que se associa, de certo modo, a mais um símbolo matemático, no caso, um algarismo: "9vidades". O termo deve ser lido e compreendido como "novidades" e é notória a substituição de parte da palavra por um algarismo que traz uma fonética parecida.

Também no quadro 3 aparecem a realização de "ke" e "neh", substituindo, assim, "que" e "né" (indicação da redução que ocorre tipicamente na oralidade para a expressão "não é?"). No que se refere à grafia do vocábulo "ke", presente também no scrap representado na figura 04, destaca-se o uso da letra " $\mathrm{k}$ ", substituindo a letra "q", mas conservando o mesmo som, havendo, mais uma vez, uma aproximação da fala. Já em "neh", o que se sobressai é a letra "h" no final da palavra, substituindo o acento agudo, critério que também é seguido na grafia de "eh" (encontrado no bilhete transcrito no quadro 14), indicando "é". A realização das notações escritas "neh" e "eh" podem ser acompanhadas em ambiente digital, respectivamente, nas figuras 05 e 12.

Por fim, no bilhete transcrito no quadro 3, aparece uma forma especial de fecho: "bjoka", na qual, dessa vez, a letra " $k$ ", ainda estabelecendo uma relação fonética, substitui a letra "c". Como a escrita sugere uma similaridade com a escrita digital, a figura 06 ilustra tal realização da escrita num scrap, de autoria de um adolescente.

Passando ao quadro 4, analisa-se um modo não convencional de grafar a palavra "tchau", trata-se de "xau". Essa escrita, também presente nos bilhetes transcritos nos quadros 5, 6 e 10, e no scrap da figura 07, reforça a ideia de aproximação com a oralidade, bastante convencionada no Orkut.

Já no quadro 5, repete-se as grafias "vc", "te dollo", "miga" e "xau", já analisadas. No entanto, mais uma grafia típica de alguns gêneros textuais da Internet aparece: "td", em vez de 
"tudo". Como acontece com as já mencionadas escritas de "tb" e "vc", ao se optar pela realização de "td", o falante registra a sequência de consoantes para representar a palavra, sem uso de vogais. A mesma escolha pode ser observada também nos scraps disponibilizados pelas figuras 07 e 17.

No tangente ao bilhete do quadro 6, mais um discente decide por escrever "XAU" e ainda repete o termo, escrevendo "XAU, XAU", outra possível aproximação da fala. Há ainda outra repetição, só que dessa vez das mesmas letras, no fim da palavra "Bjssssss", indicando "beijos". A supressão de vogais é frequente em scraps do Orkut, como ilustra as figuras 03, 07, 13 e 24, nas quais aparece a realização de "bjs". No entanto, a repetição do "s" por seis vezes em "bjssssss" não é casual, afinal indica intensidade.

Os quadros 7 e 8 elucidam o uso da abreviação "vc", mais uma vez, nos dois bilhetes. Também o quadro 9 traz uma notação escrita similar à realizada por outro aluno do $6^{\circ}$ ano e já analisada há pouco: "Bjss", sendo interessante destacar a repetição apenas de dois "s", o que aponta para uma menor empolgação se comparado ao falante autor do bilhete transcrito no quadro 6.

Já no quadro 10, além das já analisadas notações de "miga", "td", "blz", "pq", "vc", "9vidades" e "xau”, um outro registro chama a atenção: "ñ", representando a palavra "não", o monossílabo é substituído por uma só letra e o til. No scrap visível na figura 17, pode-se acompanhar a realização do "não" numa das possíveis formas da linguagem digital: " $\tilde{\mathrm{n}}$ ”.

Ao analisar-se o bilhete exposto no quadro 11, evidencia-se a construção "SZ", entendida no contexto por representar um emoticon, traduzido como um coração. Mesmo sendo manuscrito, o discente optou pelo uso dessas duas letras para efetivar o seu desenho e traduzir sua emoção, evitando o traçado convencional de um coração. Em outros bilhetes, alunos de outras séries também optam pelo desenho inusitado, sendo bastante recorrente as formas "S2" ou " $\$ 2$ ", que podem ser acompanhada nos scraps indicados pelas figuras 15, 28 e 29; tal escolha dos usuários do 
Orkut também merece realce, uma vez que o site de relacionamentos já disponibiliza um emoticon em formato de coração, $\mathrm{O}$ que pode ser observado na figura 23.

Ainda no quadro 11, pode-se enfatizar o registro de "Amu" e de "Amuuu", ambos indicando "amo". Nesse caso, a troca da letra "O" por "U" representa o som, assemelhando-se também ao fenômeno fonético que ocorre basicamente na fala e à escrita digital, representada pelo scrap na figura 06. Além de tudo, a repetição de letras na escrita de "Amuuu" enfatiza o sentimento, especialmente quando se considera o contexto em que aparece no bilhete: "Amuuu Tú". Tal ênfase pode ser acompanhada também no scrap revelado pela figura 11, mesmo não se tratando exatamente da mesma forma de escrita digital, a intensidade do "te amo" é representada através da escrita, intencionalmente pelo interlocutor, e é facilmente associável às inúmeras vezes em que as vogais são repetidas.

Agora, nos quadros 12 e 13, duas realizações bastante semelhantes que misturam ortografia convencional, linguagem digital, símbolos matemáticos e um ícone tornam-se bastante interessantes para a análise. Trata-se de "Você mora aki oh $>>>>\curvearrowright<<<<<<$ " e "Más tu mora aki oh $>>>>$ $\checkmark<<<$ ". A transcrição do ícone do coração é uma representação, visto que o desenho foi feito manualmente pelas discentes do $6^{\circ}$ ano. Todavia, o que mais chama a atenção é da utilização dos símbolos matemáticos " $<$ " e " $>$ " para indicar uma espécie de seta. Os usuários do Orkut também se utilizam desse recurso, como demonstra a figura 08 , com uma expressão bastante parecida no scrap.

Ainda nos bilhetes expostos nos quadros 12 e 13, merecem realce as notações escritas "aki" e "oh", indicando, respectivamente "aqui" e "ó" (indicando a redução que ocorre na fala para "olhe”). A realização da grafia "aki”, que já apresentou escrita similar, inclusive no scrap que aparece na figura 09, sugere a troca do dígrafo "qu", novamente por aproximação de processos fonológicos. Também "oh”, realização tão próxima da fala, mas com a 
utilização do "h" em vez de acento gráfico indica um traço bem peculiar da linguagem digital. Tal escrita pode ser acompanhada no contexto do scrap representado pela figura 31, no qual um usuário do Orkut, ao divulgar um vídeo, utiliza a frase "tricolor faz isso ai oh".

Voltando ao quadro 12 , destaca-se a repetição de vogais no registro de "ADOOORO". Esse registro aponta para a intencionalidade do autor de enfatizar o sentimento expresso no bilhete. Tal repetição de letra para indicar intensidade pode ser acompanhada também na construção "Bjaao", que aparece no bilhete transcrito no quadro 13 , bem como no scrap representado pela figura 19.

Por fim, no quadro 13, além de outras notações já analisadas e similares àquelas que ocorrem no ciberespaço, como "miguxa", "te dollo", "vc" e "tb", mais um registro destaca-se, especialmente por mesclar símbolos matemáticos e letra para assumir forma semelhante a de um emoticon, sendo, inclusive, o atalho, isto é, a forma analógica de, através do teclado do computador se chegar a forma da representação de um sorriso largo no MSN, trata-se de " =D ". Dentre os scraps do Orkut tal forma de escrita também pode ser encontrada e com o mesmo significado, perceptível ao se analisar o contexto, como ilustra as figuras 18 e 19, sendo que nessa última a alegria é enfatizada com a repetição da consoante " $\mathrm{D}$ ", indicando mais sorrisos.

Partindo para a análise do bilhete disposto no quadro 14, repete-se a escrita de "vc", "eh", "pq", mas, além dessas notações que podem ser associadas àquelas realizadas em scraps do Orkut, aparecem "mto" e "mt", indicando "muito" e denotando mais uma vez o processo de redução de palavras a partir da supressão de vogais, presente também no site de relacionamentos em questão, como demonstra os scraps das figuras 11 e 13. Supressão ocorre ainda no registro de "q", indicando o monossílabo "que" por uma letra, como na figura 10.

Outros dois fatos também se destacam ao se analisar a escrita desse bilhete, o primeiro deles é uma forma peculiar de 
escrita na qual se dobram algumas vogais ("essenciaal", "neem", "noovidaade, "tuudo", "boom", "vaai”e "assiim”), transparecendo certa preferência estilística do autor, uma vez que o gênero não é composto só por um conteúdo temático, ou por uma construção composicional, mas também pelo estilo, como aponta Bakhtin ([1979] 2003). Uma escrita similar a essa, com a duplicação de vogais, sugerindo certa euforia por parte do interlocutor, aparece também nos scraps expostos nas figuras 14 e 15. O outro critério utilizado para scraps escrita que diverge da convencional e aproxima-se da digital, mesmo tendo o papel como suporte é a manutenção apenas da primeira vogal e das demais consoantes que constituem a palavra na hora de realizar a abreviação: "amzd" e "agnt", representando "amizade" e "a gente" (que provavelmente seria escrito "agente" pelo aluno, constituindo, assim, um desvio ortográfico, segundo a norma padrão da língua). O mesmo critério foi seguido, só que dessa vez no Orkut, para a escrita das palavras "obrigada" e "recados", sendo grafadas como "obgd" e "recds", como demonstram as figuras 16 e 17.

Ainda no quadro 14 aparece a notação "HAUAHA", onomatopeia para representação do riso, bem semelhante à que aparece no scrap representado pela figura 32. A escrita "u.u” representa mais um emoticon, grafado a partir de sinal de pontuação e letras, nesse caso, representando os olhos, aparentemente cerrados. As inovações em relação à escrita convencional aparecem também no registro de "bzu", indicando "beijo" e, mais uma vez, atestando as várias formas para um mesmo vocábulo propiciadas pela linguagem digital. No caso do termo "Bzu" percebe-se a tentativa de aproximação ao som de uma oralidade infantilizada.

Finalmente, no quadro 15, é transcrito o último bilhete pertencente ao corpus referente ao $6^{\circ}$ ano do Ensino Fundamental. Na produção aparece a realização "te adollo", que, assim como "te dollo", pode ser associada à aproximação da fala infantil, indicando afetividade. 
Ao buscar-se analisar os 30 bilhetes recolhidos no $7^{\circ}$ ano do Ensino Fundamental, destaca-se que em 18 aparecem vestígios da linguagem digital, mesmo sendo utilizadas folhas de caderno dos alunos como suporte. Como prevista, segue a transcrição de tais bilhetes:

\section{Quadrol6:}

I@i parceiro de boa, como vai?

Eu sei que você ta apaixonado por Thais não presciza negar tá na sua cara / (zuação) (Fuiii)

\section{Quadro 17:}

\section{Amiguxa}

E ai piriguete! Como vc vai? Quando eu te conheci eu falei, poxa mais que menina chata, insoportada.

Quando eu estava de mau com vc eu fiquei muito triste porque não poderia conversar. Xao

Quadro 18:

Janaina.

como amigo te Dollo !!!

(:) pois eu estou muito $(;):)$

com isso que aconteceu nossas pazeses

THAU ou como você diz XAU

Quadro 19:

Geovana-linda Geovana- maravilhosa Geovana-inteligente BJsss! 
Quadro 20:

Rebeca,

Te amoooo minha (PRINCESS).

Beijões e abraços Monique

Quadro 21:

Olá, amr!

E ai como vc está?

Estou com mtas saudades de vc, só em pensar que agente não pode mais conversar pelo ork, fiko muito triste. Saiba que eu nunca vou tem eskecer, sinto $\mathrm{mt}$ falta das nossas conversas engraçadas, do sue carinho por mim; te gosto mto amr; com vc descobrir o que é uma verdadeira amizade. Te desejo tudo de bom amr, que vc seja mt feliz e que um dia agente volte a conversar

Bjosssssssss!!! Te amo00000000!!! Te adorooo000000 !!! Fika com Deus!!!

Quadro 22:

Miguxa Júlia,

Queria saber se você pode ir na minha casa hoje de tarde, às 00.02 horas; Beijos, Karen

Quadro 23:

Livia vê se mim liga pra marca o cine

Bjss miga.Te DOOLO 
Quadro 24:

Man

Ti amo - mais qui chocolate

Ti amo - mais qui orkut

Ti amo - mais qui mns

Ti amo - mais qui ir pro som lá-lá-lá ${ }^{123} \ldots$

Te amo muito, tá pra nascer algo maior que meu amor por ti nesse mundo!

Tii DOLLO S2

\section{Quadro 25:}

\section{Rebeca}

Você é muito BFF. Tradução= Best Friend Forever

Te adimiro muito.

Felicidades no $\mathbf{S 2}$

Quadro 26:

\section{Amiga}

Vou pedir a seu pai para você ir para horla.

BJS! Amo vc!

\section{Quadro 27:}

Oi amiga

Você sempre será a minha melhor amiga, depois de você vinheram várias amizades mais a sua sempre será a principal. Beijos! 
Quadro 28:

Oi amiga Blz estou com saldades

preciso te contar uns Babado do colégio -Status.

Bjos de sua amiga Julia. Se puder me liga...

Quadro 29:

Olá amiga

Fiz este bilhetinho par dizer que sua amizade para mim é muito importante, e se um dia a gente brigar não se esqueças que seu jeito de ser ficou marcado no meu coração. Te dollo!!!

Quadro 30:

Lorena!!!

Se um dia eu falar alguma coisa que vc não goste não ligue é da boca para fora mas na verdade eu "te amo" como amiga tá. Te Dollo Amiga!!!

Quadro 31:

Oi amiga

Nossa amizade estar assim: FIRME ALEGRE FORTE TE AMO BJS!

Quadro 32:

lai Karen,

Aff...vc tá toda estranha comigo depois que voutô a falar com Júlia de novo!!!

Para disso velho!!! Vc ñ responde + os meus e-mails e nem entra + no MSN!!! :-(

Pq vc tá assim??? Ela é toda indecisa, ñ sabe o que quer. No msn dia q ela fala com tu já ta briganduh!!! Bjsss!!! 


\section{Quadro 33:}

Oi: Raissa hiae beleza estou com muita saudades não vejo você faz pakas, você pra mim é uma irmã você e broder nunca vou te abandonar valeu

Eu Te Amo!

Ao iniciar-se a análise do corpus recolhido no $7^{\circ}$ ano, no quadro 16 acompanha-se o registro inusitado do vocábulo "I@i”, representando a expressão "E aí?", que já foi mencionada. Todavia, a utilização do símbolo “@” torna a produção escrita ainda mais interessante e associável à produção escrita em ambientes digitais, uma vez que é um caractere utilizado obrigatoriamente num endereço de e-mail, antes do nome do provedor no qual o usuário da Internet está cadastrado. Além da figura 20, que indica o scrap com a grafia de "iai", pode-se associar à grafia construída por esse aluno do $7^{\circ}$ ano a escrita dos próprios nomes dos usuários do Orkut, que aparecem, respectivamente, nas figuras 02, 11 e 13: “Oliveir@@@@; “@IndridDJ"e“Ren@n@@ndrade”. Também no quadro 16, registra-se a grafia "Fuiii", na qual a repetição das últimas vogais sugere intensidade, que seria perceptível na fala, propiciada especialmente pela entonação. Conforme já mencionado, nos scraps do Orkut é recorrente a utilização desse recurso, como bem exemplifica a figura 11.

No quadro 17, além da abreviação "vc", já analisada, aparecem duas palavras grafadas de maneira diferente, inclusive no meio digital, denotando as várias formas possíveis para um mesmo vocábulo, propiciada pelo ciberespaço: "amiguxa”, mais uma forma de representar "amiga" no "miguxês"; e "xao" substituindo "tchau", na escrita convencional, ou "xau", uma outra forma possível de linguagem digital.

E é justamente a escolha pela grafia "xau" a realizada pelo autor do bilhete transcrito no quadro 18, ratificando a maior liberdade de escrita típica de alguns gêneros emergentes da mídia digital, que é observada também nos bilhetes trocados em sala 
de aula, possivelmente pelo seu teor de informalidade e grau de intimidade entre os interlocutores. O próprio discente escreve em seu bilhete "THAU ou como você diz XAU !!!”, comprovando a intimidade pressuposta.

Ainda no quadro 18, repete-se a escrita da expressão já investigada "Te Dollo". Mas outra opção do autor também chama a atenção: o uso de emoticons de duas formas. Na primeira delas, o discente faz uso de desenho, duas vezes, representando um ícone conhecido como smilie: " $\supsetneqq$ ”. Todavia, em seguida, ele opta por mesclar sinais de pontuação e registrar “:-) "; mais uma vez há o registro do atalho do teclado que seria utilizado para se produzir a imagem na tela de um computador.

Já no quadro 19 e 20 aparecem, respectivamente, os registros de "BJsss" e "amoooo", ambos já analisados, especialmente pela repetição de letra para indicar a intensidade, e com escrita similar nos scraps disponíveis nas figuras 03, 07, 13 e 24, para "BJsss", e figuras 11 e 15, para "amoooo".

Ao partir para a análise do quadro 21 , destaca-se como representante de uma grafia peculiar, semelhante à escrita digital, mais uma vez a repetição de letras para indicar uma intensidade e ênfase mais comum na oralidade: as palavras "Bjosssssssss", "amooooooooo" e "adorooooooooo". Além disso, o autor do bilhete escreve "mtas", "mt" e "mto" para abreviar "muitas", "muita" e "muito", optando pela supressão de vogais, tão comum na linguagem digital, como pode se observar nas figuras 11, 13 e 18. Outra abreviação que se destaca nesse bilhete é "ork", uma criação especial do aluno que só é entendida no contexto: “[...] só em pensar que agente não pode mais conversar pelo ork, fiko muito triste". Considerando esse trecho do bilhete, a compreensão da abreviatura é alcançada: "ork" representa "Orkut".

Ainda no quadro 21, pode-se acompanhar além dos registros já analisados de "amr" e "vc", a escrita de "fiko" e de "eskecer", nas quais a letra " $\mathrm{K}$ " substitui " $\mathrm{c}$ " e "qu", indicando, mais uma vez, aproximação com a fala. 
Nos quadros 22 e 23 aparecem novamente as expressões "miguxa" e "miga", como variante de "amiga". Ainda no bilhete do quadro 23, ocorre o registro de "Bjss" e "Te DOOLO", dois termos já analisados e bastante recorrentes nos corpora desse trabalho, seja nos bilhetes dos alunos ou nos scraps recolhidos no Orkut.

Já no quadro 24 acompanha-se o registro da expressão "Ti amo mais qui", repetida quatro vezes. As grafias de "ti"e "qui" indicam uma aproximação da fala, como já mencionado, um critério bastante utilizado para registrar o internetês. O scrap disponível na figura 03 apresenta o registro de "ti", na expressão "ti dollu", bem similar a "Tii Dollo", que também aparece no recado do quadro 24. Mais uma vez a construção que hibridiza letra e algarismo para representar um coração surge no corpus: "S2", que foi escrito nos bilhetes dos quadros 24 e 25.

Outras escritas já analisadas estão, mais uma vez, disponíveis nos bilhetes dos quadros 26, 27, 28 , 29, 30, 31 e 32 , trata-se da repetição de "bjs" ou "bjsss", "vc", "Te Dollo", "blz" "Iai", “ñ", "pq", “q", “+” (indicando mais).

Ainda no bilhete exposto no quadro 32, destacam-se duas construções que indicam proximidade com a fala: "aff" e "briganduh", representando "ave" e "brigando". No português do Brasil, a expressão "Ave Maria” é bastante utilizada, bem como a sua redução para "ave", com carga semântica de interjeição, ou mesmo "afe", indicando troca das consoantes lábio-dentais "v" por "f", traço da oralidade. Também é válido destacar nesse bilhete o registro de mais um emoticon utilizando sinais de pontuação: ":-( ", nesse caso para expressar, no contexto, tristeza, uma emoção humana.

Para findar a análise dos bilhetes produzidos por alunos do $7^{\circ}$ ano da escola particular em questão, destacam-se, no bilhete transcrito no quadro 33, as grafias "hiae" e "pakas", ambas representando expressões informais: "E aî", que já foi grafada de diversas formas no corpus analisado, mantendo mais uma a tentativa de reproduzir a fala; e "pacas", termo coloquial, que 
indica "muito", mas substituindo o "c" pelo " $\mathrm{k}$ " e mantendo o mesmo som.

A seguir, foram transcritos bilhetes registrados por 8 dos 16 alunos do oitavo ano. Novamente há uma escrita, em algumas palavras, muito semelhante à escrita exposta nos scraps e em alguns bilhetes transcritos anteriormente.

\section{Quadro 34:}

oi ĺcaro.tudo bem?

Fala para Lupi que ele é feio e valente (parece um rato com raiva) kkkkk Xau

Quadro 35:

Amiga

E o jogo? $<3$

Te amu...Bjs

Quadro 36:

Rafa, mlq, blz?

Quando tiver um jogo do Flamengo com o São Paulo eu te ligo aí a gente vê que é que vai ganhar.

\section{Quadro 37:}

Gy, você para mim é minha amiga que eu posso confiar, com você mim desabafo, sei que sou chata, né?Não sei como você mim atura, é né amiga é para essas coisas $\mathbf{k k k k}$

Te doluu amiga! Beijos!!

Quadro 38:

lai Mary, como foi o final de semana?

Quadro 39:

Stephane,

Você tem novidades? Poxa eu to torcendo pra Rafael me tirar do grupo dele de geografia, ele é muuuuito chato.Bjs!!!! 


\section{Quadro 40:}

Matheus você é um amigo muito chato, idiota, ridículo, jumento mesmo assim eu gosto muito de você.Você é um amigão, gente boa. Vlw.

\section{Quadro 41:}

Mari espero que vc seja feliz, e que também mesmo que um dia acontecer de eu ou vc morar em um lugar diferentes sejamos ainda amigas. BJS XAU!

No recado exposto no quadro 34, chama a atenção, mais uma vez, a notação "kkkk", também presente no scrap indicado na figura 22. Trata-se de uma representação do riso, com caráter, assim, onomatopaico. Tal realização da escrita também aparece no bilhete exposto no quadro 37 e apresenta a mesma carga semântica.

Voltando ao quadro 34, outra escrita, mesmo tendo como suporte o papel, apresenta semelhança com a escrita digital: "xau", novamente substituindo "tchau". Esta notação escrita aparece, como já mencionado, no scrap exposto na figura 07. O mesmo vocábulo foi encontrado em outro bilhete, transcrito no quadro 4l, e, em todos os casos, apresenta a já comentada aproximação com a fala, muito comum no Orkut.

Partindo para o quadro 35, destaca-se, mais uma vez, a grafia das palavras "amu" e "bjs", respectivamente indicando "amo" e "beijos". Além disso, merece realce em tal bilhete o registro do ícone " $<3$ ", no qual a associação de um símbolo matemático a um algarismo representa um coração.

No quadro 36, destacam-se o registro de "mlq" e "blz", mais uma vez apontando a redução de palavras, assim como em "bjs" (quadro 35), observa-se a sequência de consoantes representando palavras, sem uso de vogais. Exemplos excertos do Orkut, novamente, comprovam a realização dessa grafia em scraps de adolescentes, como mostram, respectivamente, as figuras 20 e 01 . 
Prosseguindo a análise, no quadro 37, além do já mencionado "kkkk", chama a atenção a expressão "te doluu", registro também comum em textos no Orkut, mesmo com a variante "te dollo", que também indica afetividade , uma possível imitação da fala infantil, e representa semanticamente "te adoro". Na figura 03 , pode-se acompanhar o registro desse termo no scrap, dessa vez idêntica à realização encontrada no bilhete do quadro 37.

Além de tais exemplos, no quadro 38, outra vez um registro pode ser associado à migração da escrita digital para fora do ciberespaço: "Iai”. Já no quadro 39, acompanha-se, assim como em outros bilhetes analisados a repetição de vogais, para enfatizar uma ideia: "muuuuito". Nesse exemplo a vogal foi repetida quatro vezes, indicando uma intensidade que poderia ser percebida, possivelmente, na oralidade. Tal registro pode ser testemunhado na figura 23 e casos semelhantes de repetição de letras ocorrem também em outras figuras. É importante destacar que a quantidade de vezes que a vogal ou consoante será repetida na palavra varia bastante.

No quadro 40, aparece transcrito o vocábulo "vlw", que indica "valeu". Além da ausência de algumas letras, é interessante o uso do "w", apontando, novamente para uma aproximação com a fala, exatamente como aparece no scrap representado pela figura 24 .

Finalmente, no quadro 41, além do registro, no bilhete, das já analisadas grafias de "BJS" e "XAU", destaca-se novamente a abreviatura "vc", na qual, mais uma vez as vogais foram suprimidas e a sequência de consoantes representa a palavra; nesse caso "você".

Agora, ao tomar como corpus os bilhetes recolhidos no $9^{\circ}$ ano do Ensino Fundamental, percebe-se que dos 25 textos confeccionados pelos alunos, 10 não apresentam nenhum vestígio de linguagem digital. Assim sendo, os 15 textos que apresentaram alguma semelhança com a notação escrita dos textos digitais serão transcritos nos quadros a seguir. 
Quadro 42:

Oi Erika

Alguns dias você não fala comigo, mas sempre você está alegre com tudo o que tem na vida. Bjs,Vini

Quadro 43:

Iai Vinicius

Você é meu amigo e tem que melhorar pois é muito nulei no GC. XAU

Quadro 44:

Oi, Vinicio!

lai maninho, apesar de todas as nossas brigas estou aqui escrevendo pra dizer que você é meu broder e que você é um grande amigo.

Xau um abraço.

Ass: Matheus Maia.

Quadro 45:

lai Assis,

Vamos jogar brand chase e vamos fazer quest e não PVP por que vc e fraco $d+$ no be $n b$.

Quadro 46:

laê Dessa

Quero te falar que vc é muito especial; a maluca que mais gosto.

-Te adoro Beijoos!!! 
Quadro 47:

\section{E aí Suh,}

Cmo tá o pessoal ai manda um bjo pra todos, ah os meus 15 anos vêm aê rsrsrs...

Prima amr, tou te esperando akê pra resenhar e as nossas traquinagem que saudade, vc lembra qdo a gente pulou a janela na casa de praia umas 01:00 hs da manhã para irmos na boate foi Mara ai ai que tempo bons aqueles principalmente pq akela fase já passou.

S2 xau bjos Thaís

Quadro 48:

Eai lek Tudo rex.

Eai vamos dar um role domingo á tarde, lá pela praça, tomar um refri.

Só de zuera pelas quebradas, juntos com os brodes.

Quadro 49:

Amiguinha Linda! (:

[aaaaa] Amiga, eu te amo muito, muito mermo. Estarei com tgo num momento chamado SEMPRE! Nossas resenhas, nossas festas, nossos micos. HAHA e no dia que tu se mijou na rua em miga? КККККККК muito bom, tudo com tgo é bom amiga. (AAAAA), sempre serei sua conselheira, estou aqui sempre pra te ajudar. 
Quadro 50:

\section{Oie Drica ...}

Tenho algo a dizer...Que te amo

Saiba que sempre estarei contigo, dezde os momentos difíceis até os de alegria. (:

Bjos ...:p

Quadro 51:

OOi, Minie.

Caracaz que Saudades de vooc!Preciso muito conversar cte! *_*

Vê see apareçe! Beijo- Bia.*

\section{Quadro 52:}

\section{Colé irmão}

Aew fazendo o que da vida e as novidades?

Pow vey bo malhar hoje 13:00 horas, depois noix sai pra da um role,

FLW Tô saindu abç $t+$

Quadro 53:

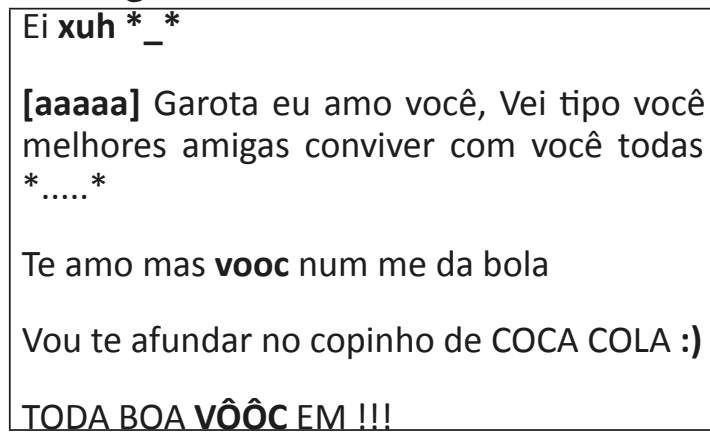
*.....*

Te amo mas vooc num me da bola

Vou te afundar no copinho de COCA COLA :) melhores amigas conviver com você todas as manhas é tudo 
Quadro 54:

lae Kéuh

Como tá tu clg? Espero que ótima!

Te Adoroõ "Melhõras!

Beijoos! =* Bý: Jokasta

Quadro 55:

Eaé Brodii, tou morrendo de saudades de você!

Vc pra sempre aki no meu *S2* .

Assinado: \{Matheus Libórioo\}

Quadro 56:

\section{laêê Brother}

Eu quero lhe dizer que vooc é uma pessoa muito gente boa.

Gosto muito de vooc (L' Te adoro

Muitas saudades *_-_- ;*

Já nos primeiros bilhetes transcritos nos quadros 42,43 , 44,45 e 46, são repetidas realizações de escrita semelhantes à escrita digital e já analisadas neste trabalho; são elas: "bjs", "Iai", "xau", "vc", "d+", "Iaê" e "Beijoos".

A partir do quadro 47, mesmo repetindo-se os registros "bjo(s)", "pq", "amr", "vc", "xau” e o ícone "S2", outras construções chamam a atenção, justamente por também associarem-se à linguagem digital. Duas dessas realizações de escrita são "cmo" e "qdo", em que o autor reduz a palavra a apenas três letras, conservando apenas a última vogal. Outra construção que merece análise é "aê", em vez de "aî", que pode ser associada, inclusive, às construções "Hiae", "Iae", "Iaê" e "Iaêêe", que aparecem em meio aos próprios corpora deste trabalho, apontando para uma 
aproximação da oralidade e sugerindo certa ênfase. Também sugerindo essa imitação de fala aparece a palavra "akê", que pode ser acompanhada também no scrap da figura 28, indicando a lexia "aqui". Além disso, nesse vocábulo aparece a troca de "q" por " $k$ ", sem prejuízo fonético e seguindo o mesmo critério utilizado para a escrita de "akela". Por fim, no quando 47, destaca-se a construção "rsrsrs", também muito comum na linguagem digital, apresentando mais uma vez um caráter onomatopaico ao representar o som do riso.

Já no bilhete transcrito no quadro 48 , além de mais uma vez aparecer a expressão "Eai", destacam-se duas criações especiais, "lek" e "rex", em que só o contexto possibilita a atribuição de significado: "Eai lek Tudo rex", que poderia ser traduzido como "E aí, moleque, tudo relax"?, sugerindo, inclusive, uma influência do idioma inglês.

Ao avaliar-se a escrita presente no bilhete exposto no quadro 49, enfatiza-se o termo "com tgo", no qual a autora separa a palavra "contigo", troca o " $n$ " pelo " $m$ " e suprime a vogal "ip". Também merece realce a repetição da letra "a" nas construções "[aaaaa]" e "(AAAAA)", que podem ser associadas à interjeição "ah!” e sua repetição à ênfase pretendida pela falante, também se assemelhando a uma prolongação que poderia ocorrer na oralidade. Recursos onomatopaicos a partir de repetição de letras também são utilizados por esse discente do $9^{\circ}$ ano, ao grafar as expressões "HAHA" e "KKKKKKKK", que podem ser associadas às onomatopeias presentes nos scraps que aparecem nas figuras 22 e 32 . Há, ainda, o registro dos já analisados emoticons a partir de sinais gráficos " (: ", representando o sorriso, como na figura 21 e o aparecimento de um outro ícone: "(L)", que também aparece no scrap da figura 29, inidicando o atalho para se representar um coração no MSN.

Também é o uso de caracteres para representar um emoticon que chama a atenção no bilhete reproduzido no quadro 50: ": p", que pode ser assimilado ao ato de "dar língua"; interessante destacar que o uso dos dois pontos, bem como da letra "p", 
aparece também no scrap disponível na figura 30 e é, mais uma vez, o atalho usado para o aparecimento de um emoticon disponibilizado pelo Messenger. No mesmo bilhete, repetem-se ainda as construções ":)", “oie" e "bjos”, todas já analisadas.

Já no bilhete explicitado no quadro 23, mais uma vez símbolos representam expressões faciais, trata-se de “*_*”, escrita que também pode ser acompanhada no scrap da figura 08. Além de tudo, novamente é necessário se recorrer ao contexto para se compreender uma abreviação em mais um bilhete, trata-se de "cte", que aparece na seguinte frase: "Preciso muito conversar cte!". Pelo contexto, pode-se traduzir a criação especial "cte" por "contigo". No mesmo bilhete aparece a duplicação de vogais em "see", substituindo "se", e "vooc", em vez de "você". Nesse último caso, há ainda a supressão da última vogal, exatamente como o vocábulo grafado no scrap exposto na figura 14 .

$\mathrm{O}$ quadro 52 traz a transcrição de mais um bilhete com escrita peculiar, na qual chama a atenção a expressão "Pow vey bo malhar...”, em que as marcas de oralidade são muito fortes e a coloquialidade dos termos seria visível na reescrita para a grafia tradicional: "Pow"= "Poxa"; "vey"= "velho" e "bo" como redução de "vamos embora". As construções "Pow" e "vey" destacam-se pelo uso das semivogais "W" e "Y", e podem ser vistas também nos textos dos scraps das figuras 25 e 26. Outra notação escrita também se destaca: "FLW", indicando "falou" e muito similar ao processo de formação da grafia que substitui "valeu", o vocábulo "VLW", no bilhete já analisado. Ineditamente, no corpus composto por bilhetes, aparece a realização da palavra "noix", em vez de "nós", na qual o uso do "x" substituindo o " $\mathrm{s}$ " sugere uma aproximação da fala, bem como adesão ao "miguxês"; uma realização parecida consta no scrap da figura 07: "saudadexxx", substituindo "saudades". O autor do bilhete também faz uso da abreviatura "abç", para substituir "abraço"; e "saindu" em vez de "saindo", representando uma aproximação fonética; ambas opções do falante são bastante comuns também por parte de usuários do Orkut. Ainda, repete-se a construção 
"T+", indicando a frase "até mais" que também já foi comentada neste artigo.

Já no quadro 53, o bilhete traz o termo "xuh", no qual o "h" parece substituir um acento gráfico no final da palavra, mesmo esse sendo desnecessário, nos moldes da ortografia tradicional, uma vez que se trata de um monossílabo tônico terminado em "u". Outras realizações já analisadas neste artigo podem ser revistas nesse bilhete: “*_*”, "[aaaaa]", "vooc", “:) " e "VÔỐC"; todas com a mesma carga semântica descrita anteriormente.

No quadro 26, além dos já investigados vocábulos "Iae", "Adoroô", "Beijoos", aparece a abreviatura "clg", que indica "colega", e repete o critério no qual a sequência de consoantes representa a palavra. Também se destaca mais um emoticon para representar beijo, utilizando símbolos disponíveis no teclado do computador: " $=$ * ", construção similar e de mesma significação pode ser acompanhada no scrap da figura 27.

Ao analisar-se o bilhete do quadro 55, destaca-se, mais uma vez, a repetição das vogais finais, nesse caso específico, em dois termos: "Brodii" e "Libórioo", representando, com certa ênfase, a sonoridade da palavra inglesa "brother", e "Libório", o sobrenome do próprio autor. Ainda no mesmo bilhete, repetemse as construções "Eaé", "vc", "aki" e "S2', semelhantes à escrita digital e já ponderadas neste trabalho.

Por fim, no quadro 56, além das recorrentes notações "Iaêê", "vooc", merecem destaque os símbolos que retratam emoções, como "L" (bem próxima à realização que aparece no scrap da figura 30), “*-.--*” (semelhante ao scrap da figura 30) $\mathrm{e}^{\text {" }} ;^{*}$ " (também presente no scrap da figura 27$)$, cada um com significação própria.

\section{Conclusão}

A análise dos bilhetes encontrados em atividades escolares permite afirmar que há algum indício de escrita digital em suportes diferentes do computador. Trata-se então da possível 
transmutação da transmutação, uma vez que são investigados scraps do Orkut, considerados a transmutação do gênero bilhetes, mas também, quando proposta aos 96 discentes a escrita de bilhetes, mesmo usando o papel como suporte, muitos deles (cerca de 58,33\%) utilizam-se, vez por outra, de palavras que apresentam a grafia da escrita digital.

Ressalta-se, ainda, que devido à limitação dos corpora, os resultados obtidos na análise dos dados não devem ser determinantes para afirmar que há sempre uma influência da escrita digital em bilhetes escritos por jovens em outros suportes diferentes do computador. Mas a pesquisa contribui para a reavaliação e reflexão sobre a importância da Escola em trabalhar e reconhecer, de maneira real e eficiente, as variações linguísticas, inclusive da escrita, acrescentando também as inovações oriundas dos gêneros textuais emergentes, especialmente os digitais, que surgem mediante uma necessidade sócio-comunicativa e ganham cada vez mais adeptos, sobretudo em idade escolar.

\section{Referências}

ABREU, Verena Santos. As práticas de escrita em scraps do Orkut: apenas a transmutação dos gêneros bilhetes e recados? In: RIBEIRO, Ana Elisa et al. Linguagem, tecnologia e educação. São Paulo: Peirópolis, 2010.

ARAÚJO, Júlio César. Chat na Web: um estudo de gênero hipertextual. 2003. 157f. Dissertação (Mestrado em Linguística) - Programa de PósGraduação em Linguística da Universidade Federal do Ceará, Fortaleza, 2003.

BAKHTIN, Mikhail. Estética da criação verbal. 4. ed. São Paulo: Martins Fontes, [1979] 2003.

BISOGNIN, Tadeu Rossato. A escrita no Orkut: vocabulário mais utilizado e aproveitamentos do internetês para o ensino de língua portuguesa. In: COUTO, Edivaldo Souza; ROCHA, Telma Brito (Orgs.). A vida no Orkut: narrativas e aprendizagens nas redes sociais. Salvador: EDUFBA, 2010. 
MARCUSCHI, Luiz Antônio. Gêneros textuais: definição e funcionalidade. In: DIONÍSIO, Angela Paiva; MACHADO, Ana Rach; BEZERRA, M. A. (Org.). Gêneros Textuais e ensino. Rio de Janeiro: Lucerna, 2002.

. Gêneros textuais emergentes no contexto da tecnologia digital. In: MARCUSCHI, Luiz Antônio; XAVIER, Antônio Carlos. Hipertexto e gêneros digitais: novas formas de construção de sentido. Rio de Janeiro: Lucerna, 2004. 